\title{
A DUPLA INTERPRETATIVIDADE DO DEVER-SER *
}

\author{
Luiz Fernando Coelho **
}

\section{O DEVER-SER NA “TEORIA GERAL DAS NORMAS"}

A “Teoria Geral das Normas"', de Hans Kelsen, vem a ser uma epistemologia das ciências ditas normativas, definidas pelo próprio autor como sendo aquelas cujo objeto é constituído por normas, sentido que ele trata de cuidadosamente distinguir e preservar. Com esta obra, publicada postumamente, talvez pretendesse Kelsen participar da polêmica em torno dos limites e possibilidades da lógica deôntica, mis o resultado mais notável de seu trabalho foi a sistema.tização de um modelo analítico para as ciências normativas, abrangendo a Ética e o Direito.

Dentro desse desiderato, o qual igualmente se insere coerentemente no contexto do purismo metodológico desenvolvido na "Teoria Pura do Direito", adentra Kelsen o problema ontológico do dever-ser como categoria original, abrangendo as modalidades deônticas possíveis, de imposição, permissão, autorização e derrogação². Ora, observa o autor, o dever-ser é em si indefinível, tal como o ser, por tratar-se de uma categoria que condiciona o conhecimento dos objetos normatjvos, só se podendo concebê-lo em função dos termos que relaciona.

A norma, cujo núcleo é o dever-ser, é o sentido de um ato de vontade, um querer dirigido à, conduta de outrem, e seu específico valor lógico é a validade, que identifica um processo dinâmico a envolver o estabelecimento de uma norma geral hipotética, a existência "in concreto" da condição determinada "in abstracto" por aquela e a fixação de uma norma individual categórica correspondente à norma geral; o que pressupõe o reconhe-

- Conferência proferida no Seminário Internacional sobre a "Teoria Geral das Normas". de Hans Kelsen no Curso de Pós-Graduação em Direito da Universidade Federal de Santa Catarina, novembro/87.

- Professor Titular do Departamento de Direito Privado do Setor de Ciências Jurídicas da UFPr.

(1) KELSEN, Hans, Teoria Geral das Normas. Trad. de José Florentino Duarte. 1986. Porto Alegre: Sérgio Antonio Fabris Ed. Obs. Todas as referências a seguir reportar-se-ão à tradução brasileira.

(2) págs. 3 e 120. 
cimento da norma geral hipotética pelo indivíduo que estabelece a norma individual categórica ${ }^{3}$.

Além de definir o estatuto ontológico do dever-ser, mantém o autor a tese da dupla interpretatividade do dever-ser, já proposta na "Teoria Pura do Direito". Enquanto norma, o dever-ser consiste no correlato de um querer dirigido à conduta de outrem, enquanto proposição, é o enunciado sobre a validade de uma norma. Ao exemplificar os dois sentidos, afirma o autor que os Dez Mandamentos são normas transmitidas por Moisés como estabelecidas por Deus; e que a ordem do senhor é transmitida ao criado por alguém; em outro lugar, afirma Kelsen que as normas do chamado direito natural pr sssupõem uma vontade imanente, divina ou racional, metafísica ou simplesmente ficta, tal como todos os imperativos que não possam ser reduzidos a uma relação de causalidade ${ }^{4}$.

Ora, tendo essa transmissão, isto é, o meio pelo qual o imperativo é comunicado aos destinatários, a mesma estrutura lingüística e o mesmo sentido prescritivo do dever-ser originariamente estabelecido, este envolve dupla interpretatividade, como vontade de Deus, do senhor, do pai, da razão, de um ente imaginário, e como enunciado teórico sobre aquele sentido.

Essa dupla interpretatividade, como ato de vontade e ato de cognição, tem certamente suas implicações, não somente no estatuto ontológico que Kelsen atribui ao dever-ser, como também em aspectos basilares de sua teoria, como sejam, o da definição da Jurisprudência como ciência normativa e o dos fundamentos da ordem jurídica positiva.

\section{O DEVER-SER COMO CATEGORIA ONTOGNOSEOLÓGICA}

Na Teoria Pura do Direito o dever-ser é proposto como suporte modalmente indiferente, quie se mantém em nível lógico-formal e epistemológico. Como tal, ele não tem propriamente uma dimensão ontológica, mas funciona como categoria lógico-transcendental apta a coordenar os dados da experiência definida como "jurídica", justamente porque enformados por aquela categoria. Daí que o "sollen" é o modo próprio de conhecer-se juridicamente os atos de conduta, traduzindo lingüisticamente o conceito de imputação, de igual modo como o "ser" traduz lingüisticamente a causalidade.

Com essa transcendentalização do "sollen", obteve Kelsen seu desiderato de elaborar uma teoria "pura", pois ela se mantém tão somente no mundo abstrato, logicamente anterior aos dados

(3) Påg. 62.

(4) Págs. 191/192. 
da experiência histórica que se propõe a unificar; com efeito, somente com a atribuição de sentido a um elemento de fato, o qual não se confunde e nem se identifica com o efeito causal, é possível conceber-se um substrato que se mantém no mundo ideal, indiferente às modalidades que dele se possam extrair.

Na Teoria Pura do Direito o "sollen" é o substrato modalmente indiferente que esgota o jurídicc, isto é, único meio de acesso cognoscitivo ao objeto, e rieste particular modo imputativo de conhecer radica o núcleo da juridicidade, passível de ser formulada lógica e lingüisticamente pela fórmula "Se A, deve ser B".

$\mathrm{Na}$ Teoria Geral das Normas o dever-ser assume o status de categoria ontognoseológica, precisamente em função de sua dupla interpretatividade, como expressão de um querer, pressuposto, ainda que fictício, e como expressão cognoscitiva desse querer, abrangendo esta segunda interpretação o nível comunicacional do conhecimento dirigido à rorma.

Poder-se-ia então asseverar que Kelsen se converte ao concretismo jurídico? Daria o autor razão a Reale, que entende a juridicidade como dialética implicação dos elementos objetivos de fato, norma e valor, expressados pela norma? Ou a Cossio, com sua concepção de norma como o meio normativo de acesso cognoscitivo ao ser jurídico, identificado na conduta em interferência intersubjetiva?

Apesar de que a Teoria Gera! das Normas recupera a concepção do "sollen" como modalidade indiferente, e'a não tem o alcance que tais questionamentos sugerem. O "jurídico", no Kelsen da Teoria Geral das Normas, continua sendo a norma abstrata, "pura", funcionando como "a priori" em relação aos fatos da concreçãc jurídica; trata-se de uma objetividade analítica, a comportar uma leitura no piano lógico e outra no plano ontológico; o resultado da primeira seria a expressão da norma como conhecimento normativo; o resultado da segunda leitura, seria conduzir o intérprete-leitor à vontade normativa, a qual constitui, esta sim, o núcleo ontológico da juridicidade, mas não de uma juridicidade concreta à maneira do culturalismo fenomenológico que a tradição do pensamento latino-americano desenvolveu, mas de uma juridicidade entendida como substrato lógico-material, espécie de "a priori" material husserliano, a condicionar, não o conhecimento do objeto, mas o próprio objeto em sua manifestação histórica.

Enquanto categoria ontognoseológica, o jurídico da Teoria Geral das Normas continua sendo pressuposto e ao mesmo tempo sentido imputativo do "querer" que o produziu, por um lado, e, por outro, do saber que o trarısmitiu. 


\section{DEVER-SER E CIENCIA DO DIREITO}

Ao tratar das proposições da ciência do direito, assevera Kelsen que esta contém enunciados descritivos sobre normas, mas que estas, cujo conjunto forma o sistema de direito positivo, englobam essas duas espécies de enunciados: aqueles que constituem o correlato do querer, o qual se manifesta no processo legislativo ordinário, e aqueles qute transmitem esse sentido, através das normas hierarquicamente inferiores ${ }^{5}$; e assim, a rigor, em cada sistema as únicas normas autênticas seriam as fundamenta's do sistema, ou seja, as de hierarquia constitucional, já que as demais seriam tão somente derivações analíticas das primeiras, cujos enunc:ados não seriam prescritivos, mas descritivos.

A ciência do direito teria então dois níveis de preocupações: o dever-ser instituinte, o que é coerente com o conceito amplo de constituição que o autor desenvolve, e o dever-ser transmitente, manifesto nas normas regulamentares e individualizadas, inclusive as jurisdicionais e as negociais.

Toda norma válida poderia assim ser lida sob esse duplo enfoque, ou como o sentido da vontade que a teria instituido, ainda que fictícia, ou como a descrição desse sentido, segundo o processo d.nâmico que identifica a validade.

A teoria jurídica contemporânea tem enfatizado ambos os aspectos, o normativo, na lógica jurídica proposicional, e o comunicacional, na análise lingüística. Quanto à lógica do direito, ao menos no sentido estrito definido por Tammelo e assimilado por Kelsen ${ }^{6}$, a possibilidade de derivações analíticas a partir da lóg ca bivalente pressupõe aquele nível comunicacional, em que o dever-ser aparece como sentido de um ato de pensamento, e náo de um ato de vontade, o que caracteriza o nível propriamente ncrmativo do dever-ser. E quanto à análise lingüística, vale lemtrar que Capella já demonstrara a existência de uma meta-linguagem incorporada à linguagem da lei, só que enunciada na fol $\mathrm{ma}$ de indicações, definições e recomendações ${ }^{7}$, portanto, em sent do menos amplo que o traduzido pelo nível comunicacional que toda e qualquer norma envolve.

Articu'ando pois os conceitos de linguagem e meta-linguagem com os conceitos kelseniaros de norma e proposição, a partir das cons derações acima pode-se concluir que toda norma válida é passivel de dupla interpretatividade, como linguagem e metalinguagem, ou seja, que todo $\epsilon$ qualquer enunciado de um siste-

(5) Págs. 194 e segs.

(6) Páq. 349.

(7) CAPELA, Juan Ramón, El Derecho como Lenguaje. Barcelona, 1968. 
ma normativo comporta sua interpretação como norma e como proposição, no sentido estabelecido por Kelsen.

O objeto da Jurisprudência como ciência passaria assim a ser constituído não somente por normas jurídicas, mas também por proposições jurídicas expressadas normativamente.

\section{O DEVER-SER DA NORMA FUNDAMENTAL}

A teoria da dupia interpretatividade do dever-ser repercute também no problema do fundamento de validade do sistema normativo, onde Kelsen desenvolve e, de certa forma, pretende corrigir as postulações formuladas na "Teoria Pura do Dıreito".

Recordemos que, para preservar seu desiderato de construir uma teoria do direito isenta de elementos não normativos, situara Kelsen o problema do fundamento de validade nos quadros de sua teoria da Grundnorm; esta, define-a o autor como uma constituição primeira de natureza hipotética, atuando como pressuposto lógico-transcendental do sistema do direito positivo, um dever-ser apriorístico sem conteúdo, cuja validade não seria implicada pela derivação de uma norma superior, mas que seria válida por si mesma; uma validade pressuposta e hipotética que teria o condão de atuar como o fundamento último da validade de todo o sistema normativo, hierarquicamente escalonado.

Esse estatuto ontológico, que atribui à norma fundamental a natureza de uma hipótese lógico-transcendental, resguarda o principio epistemológico da pureza kelseniana, pelo qual a legitimidade do direito positivo estaria fundamentada no próprio direito positivo, sem a necessidade de apelar para as fundamentações meta-jurídicas de caráter rréafísico, sociológico, ou ideoiógico.

$\mathrm{Na}$ "Teoria Geral das Normas" reformula Kelsen esse entendimento, atribuindo à norma fundamental o status de uma ficção, porque dimanada de uma vontade também fictícia. Considera Kelsen que um ordenamento moral ou jurídico representa um sistema de sobre-e-sob-normas, a partir da constituição, fundamentada pela pressuposta norma fundamental; ou seja, a norma fundamental da primeira constituição nistórica é aquela em que se baseia o ordenamento jurídico, porque o fundamento de validade de uma norma só pode ser outra norma. Entretanto, a natureza ontológica de tal norma fundamental não radica no caráter hipotético que lhe fora atribuido na "Teoria Pura do Direito", mas no aspecto fictírio da vontade que a teria produzido"

(8) Pág. 328. 
O problema é aparentemente insolúvel, sob a ótica do formalismo kelseniano e parece implodir o princípio da pureza metodológica, pois a reformulação proposta na "Teoria Geral das Normas" introduz um elemento não normative no sistema lógico em que o direito positivo se constitui, segundo essa ótica; é que a ficção, embora seja um ente imaginário, não necessariamente hipostasiado, se pressupõe como real. O autor explica a ficção normativa como algo que é ou deve ser acompanhado pela consciência, porque a ela não corresponde a realidade; sendo essa consciência da normatividade essencial para a natureza ontológica da norma fundamental, conclui-se que um elemento de fato, extra-normativo, passa a integrar necessariamente a teoria do direito positivo naquilo que lhe é imprescindível, o fundamento de validade do sistema jurídico; ainda mais, quando Kelsen rejeita a noção de uma norma válida pelo simples fato de haver sido enunciada, pois a validade, que traduz a existência da norma, decorre do fato de haver sido posta por uma vontade, ainda que fictícia.

Nesse novo entendimento, a norma fundamental perde seu caráter de pressupostc lógico-transcendental e passa a ser histórica, não no sentido de norma positiva confundida ou subentendida no sistema, mas no de uma historicidade também ficta, a atuar como categoria ontológico-real, um a priori lógico-material do sistema de normas válidas, que são normas concretas, no mais autêntico sentido fenomenológico. Com efeito, a possibilidade de uma tal leitura fenomenológica é mais um elemento a evidenciar o abandono do formalismo, reforçado pela rejeição declarada de Kelsen à sua anterior teoria da hipótese normativa, quando atribui esta a um acidente em seu trabalho teórico 9 . $\mathrm{E}$ além disso, a teoria da ficção vem a ser uma resposta bastante feliz aos problemas suscitados pelo nivel de abstração em que a Jurisprudência fora projetada na "Teoria Pura do Direito".

Sem querer ser mais kelseniano que o próprio Kelsen, penso não existir incompatibilidade entre as teorias da ficção e da hipótese normativa, como insinua o autor, pois tal incompatibilidade se desvanece ante a dup!a interpretatividade do dever-ser.

Ficção e hipótese constituem dois planos distintos em que a questão da validade da norma pode ser encarada, os quais todavia pressupõem o mesmo modelo epistêmico analítico e a mesma concepção acerca da irredutibilidade do ser ao dever-ser. Segundo esse modelo, a norma jurídica pode ser encarada, em função da dupla interpretatividade, seja como correlato de uma atividade teórica voltada para um dever-ser objetivo, seja como essa própria atividade.

(9) Pág. 329. 
Como norma positiva, a tese de uma constituição primeira fictícia vem proporcionar, não somente um fundamento de validade do sistema de direito positivo, como também um fundamento de legitimidade, o qual atua ideologicamente como uma legitimidade imanente, porque a vontade fictícia que atua ficticiamente ao criar a norma, é também uma vontade em si mesma legítima; e assim, o sistema de direito positivo, como qualquer sistema normativo que se aceite como existente, traz em si mesmo sua própria legitimidade imanente, prescindindo de fundamentos extra-jurídicos ou meta-sistemáticos, como o direito natural ou a vontade do Estado. Esse fundamento de validade é ficticiamente real, porque o sistema normativo é real, está aí como o direito existente, portanto válido e legítimo.

Ocorre porém que o trabalho teórico transporta a norma positiva para um plano abstrato de expressão meta-lingüística, e assim, o sistema lógico-formal do modelo analítico de ciência, o qual espelha teoricamente a realidade fática do sistema normativo, sendo também um dever-ser em função da dupla interpretatividade, deve atribuir à sua própria norma fundamental a condição teórica da validade; nesse plano teórico, a validade se confunde com a legitimidade.

É aí que a noção de hipótese normativa vem atuar, correspondendo-lhe no plano teórico o mesmo papel desempenhado pela ficção no plano dos fatos.

Ao contrário do que insinua o autor, a tese da norma fundamental fictícia não corrige a anterior, da norma fundamental hipotética, mas a completa, vindo a integrar-se no elenco dos recursos fiiosófico-jurídicos que tendem a preservar os pressupostos ideológicos do direito positivo e do saber que sobre ele se construiu, a velha e rançosa Dogmática Jurídica ensinada nas Faculdades de Direito. 